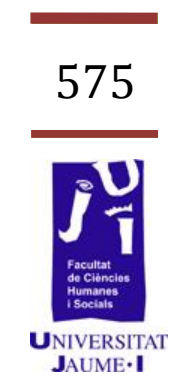

\title{
El Branding Emocional Una aproximación heurística y profesional a su metodología y campos de innovación
}

Irene Nomdedeu

nomdedeu.irene@gmail.com 


\section{Resumen}

¿Que ha de hacer una marca para "enamorar" a su público? ¿Que técnicas ha de seguir para establecer un vínculo sólido y estable con sus consumidores?

Las herramientas utilizadas para la construcción de marcas - como la proposición única de venta (USP) o la definición del ADN o esencia de marca (brand DNA o brand essence) - tienen una función meramente descriptiva. Tras la revolución del Marketing Cultural, y la demostración de la importancia de los factores psicológicos en la decisión de compra, los gestores de marcas debemos emprender un camino nuevo, basado en establecer y/o reforzar la conexión emocional con los consumidores.

El consumidor también ha evolucionado a pasos agigantados. Liberado de la "Aguja Hipodérmica" de Lasswell y Wright, el espectador inteligente evoluciona en la senda de los Usos y Gratificaciones de Katz, Blumbler y Gurevitch (1974), hasta el punto de exigir un trato personalizado, casi de tu a tu, por parte de la marcas que consume.

En un momento en que ya no se valora el "awareness" -recuerdo, conciencia- de marca sino la "calidad" del significado que ésta tiene para el consumidor, parece interesante explorar cómo las marcas más icónicas han utilizado y utilizan técnicas de construcción emocional para "gratificar" a sus consumidores y anidar en su corazón.

Estamos en la era de las marcas personalizadas, generadoras de emociones, compañeras en una relación de mutuo beneficio.

Este es una aproximación heurística al Branding que usa las emociones para conquistar a los usuarios en medio de este mundo individualista, en el que se repasan los autores, contenidos y técnicas vertidos hasta el momento, y en el que la autora pretende completar con alguna pincelada de su experiencia profesional.

Paraules clau: Branding emocional, marca icono, marca humana, marketing cultural, marketing experiencial.

\section{Introducción}

Hace unos meses, me enfrenté al reto de comprarme mi primer coche. Era el primero que iba a adquirir sin la ayuda de mis padres, así que tenía plena libertad para elegirlo. Buscando por internet, encontré un Mini rojo que me maravilló y decidí ir a verlo. Mi padre, conocedor de mi gran capacidad de sorpresa, me advirtió: "Cuando lo veas, disimula, y haz como si no te gustara" me espetó. Cuando llegué al concesionario, no 
pude evitarlo: Era el coche que siempre había soñado. Y sí, lo compré inmediatamente.

Años más tarde, pensando en frío - y con el coche con más de un rasguño por haber abusado de su capacidad de "conducción divertida" - me pregunté.. ¿Que ha de hacer una marca para "enamorar" a su público? ¿Que técnicas ha de seguir para establecer un vínculo sólido y estable con sus consumidores?

Cierto es que Mini lleva construyendo su personalidad desde hace mucho tiempo.

En uno de sus anuncios mas representativos, que vemos en un garaje aparcados a los dos minis, el antiguo y el nuevo - los dos rojos- y un titular que reza "Tener el mismo gusto que tu abuelo.. No es normal".

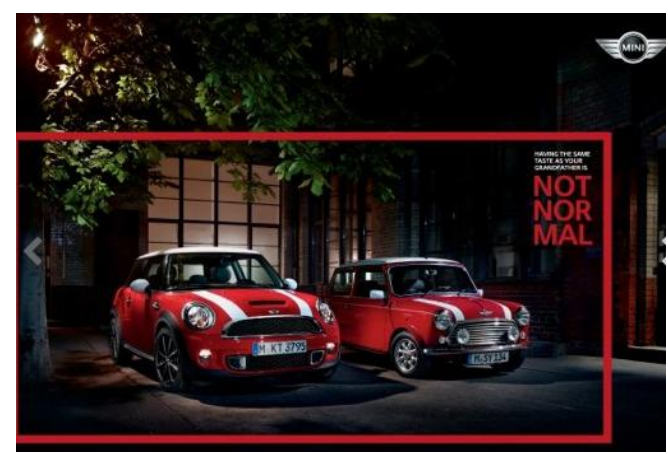

Con esta pieza de publicidad exterior vemos como Mini recurre a un primer factor "humano" en la creación de identidad de marca. La Nostalgia, (Gobe, 2005: 312) tiene la capacidad de otorgar al producto que acompaña un aire cool, retro, chic... ideal en este caso para un público joven (o que, como mínimo, aspira a parecerlo).

En sus piezas publicitarias, Mini suele utilizar como principal soporte formatos exteriores Especiales o Spectacular Outdoor. Hemos visto a Mini correteando por altísimas vallas a modo de pistas de Scalextric, o zigzagueando en medio de las páginas centrales de conocidos periódico.
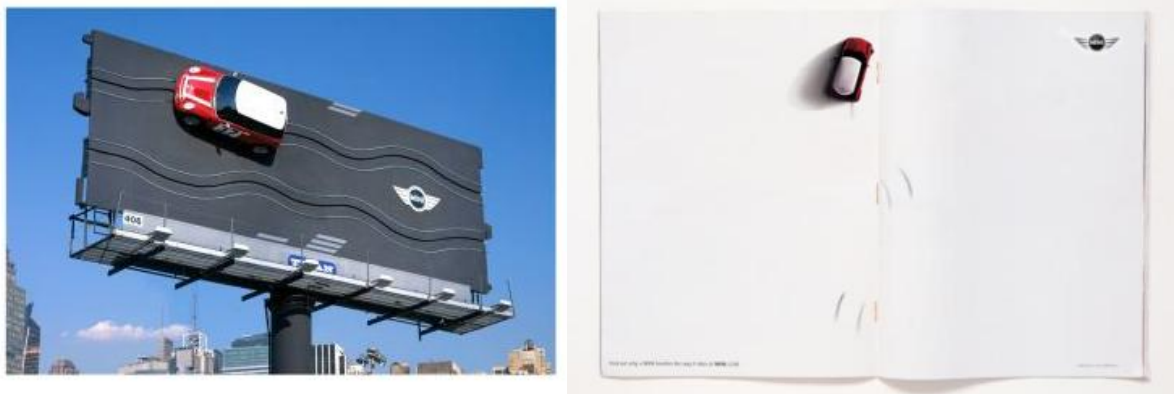

Divertido, osado, travieso, es el producto ideal para creativos singulares. En la Navidad de 2010, JWT Ámsterdam construyó cajas de cartón de tamaño del coche a modo de "regalo" navideño, y arrojó las cajas a la 
calle, enmedio de los contenedores de reciclaje de cartón. Imaginad la cara de los transeúntes al ver un envoltorio de un Mini tamaño gigante entre tetrabriks... O bien la campaña de Tewa Singapore, de 2004, en el que situaban a Mini en un pack a modo de regalo.
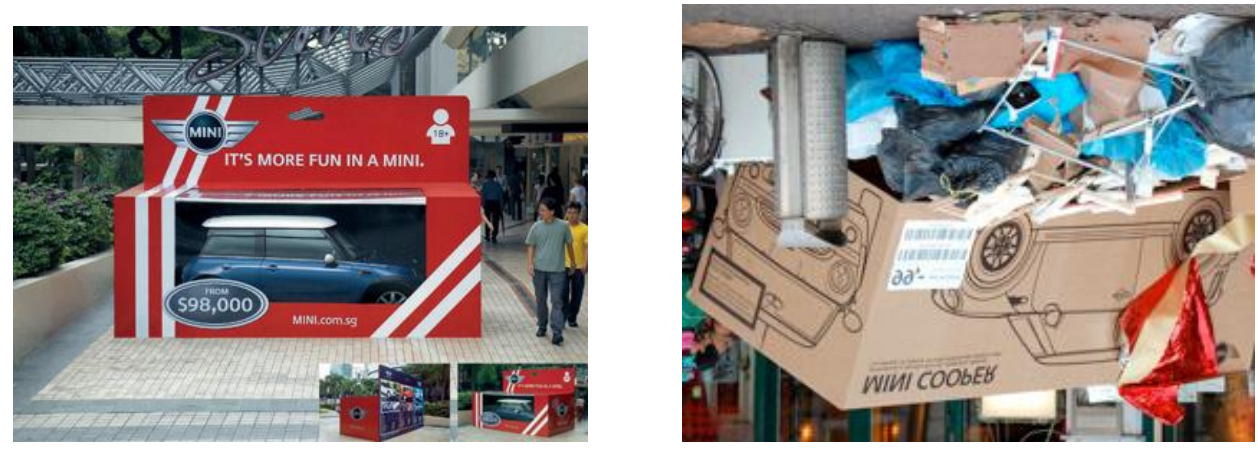

Mini es un ejemplo de comunicación que por sorprendente, despierta simpatías, va directa "al corazón".

Pero como Mini, hay muchas marcas. Marcas que han conseguido penetrar en una buena parte de la sociedad y liderar movimientos, entrar en el olimpo de las marcas, adquirir el codiciado status de "marcas culto".

Para conseguir una marca con alma, una marca de "culto", el primer paso es la definición de las características del producto y las innovaciones que incluya su construcción con el fin de encontrar su singularidad. La singularidad del producto debe vivir en el mismo producto, puesto que más tarde dará lugar al la "verdad de producto" ( product truth), o en su acepción más tradicional, a la "reason why". En el caso del Mini, fue el primer coche de ciudad hecho en UK y que competía con los coches "burbuja" alemanes de los 60, con un motor optimizado y con el máximo espacio posible en su interior. Eso si, con una excentricidad muy británica.

Una vez definido el producto, el primer paso publicitario es crear el Brand ID (brand name, logo, slogan), identificadores que actúan meramente en pro del recuerdo.

Pero no sólo con la publicidad, sino cada vez mas con las experiencias del consumidor y las leyendas construidas alrededor del producto, la marca se vallenado de contenido y de personalidad.

El uso de nuevas técnicas y tecnologías completa la construcción emocional alrededor de una marca. Hoy en día empezamos a apreciar las bondades del uso de nuevos medios, como el branded content contentido generado por la marca- , o la eficacia del uso - correcto - de celebrities que refuerzan la personalidad de la marca. En caso del Mini, se ha visto al volante de este coche a Lily Allen, Liam Gallagher o Kate Moss, personajes innovadores, diferentes, fuera del "mainstream". Tambien era el coche de Mr. Bean, hecho que sin duda potencia el carácter divertido del pequeño automóvil. 
Hoy en día, con la aparición de las redes sociales y las tecnologías 2.0., las marcas tienen además, la posibilidad de establecer un diálogo directo con sus usuarios, una interacción "de tú a tú" no concebida hasta hace bien poco.

Estamos en la era de las marcas como generadoras de emociones, como compañeras en una relación de mutuo beneficio.

Con esta aproximación al Branding de las emociones, en el que se repasan autores, contenidos y técnicas vertidos hasta el momento, y en la que la autora pretende completar con alguna pincelada de su experiencia profesional, se pretende dilucidar los principales factores de éxito en la construcción de estas marcas líderes, iconos de nuestra cultura contemporánea.

\section{Objetivos}

Dilucidar, a través de un enfoque heurístico, cómo las marcas más relevantes han utilizado y utilizan técnicas de construcción emocional para expresarse y quedarse en el corazón de sus consumidores, estableciendo un vínculo sólido y durable.

Explorar las prácticas más ejemplarizantes a este nivel.

Demostrar la nueva relación de las marcas con sus públicos, como compañeras en una relación de mutuo beneficio.

\section{Material y método}

Consulta de los teóricos más relevantes y actualización de las grandes ideas y conceptos en el campo de la Comunicación Publicitaria

Análisis Cualitativo de casos paradigmáticos.

\section{Resultados}

Factor de éxito 1: La marca tiene una historia interesante que contar.

EL CASO CORONITA: Corría el año 1980 y la cerveza Corona sólo se distribuía en el sudeste de Estados Unidos. Por aquella época, se puso de moda entre los estudiantes visitar esta zona, soleada y turística, en Pascua. Tras estas vacaciones, cortas pero intensas,los estudiantes volvían al campus con historias de playa, fiestas y diversión, donde Corona siempre estaba presente enmedio de todas las anécdotas. Además, al consumo de Corona se le añadió la lima - emulando al tequila 
- con lo que a la leyenda se le sumó el caracter de "ritual" , tan propio de los mitos. Gracias a esta suma de elementos benefactores a la marca, Corona se puso de moda y se alzó como lider de ventas en poco tiempo.
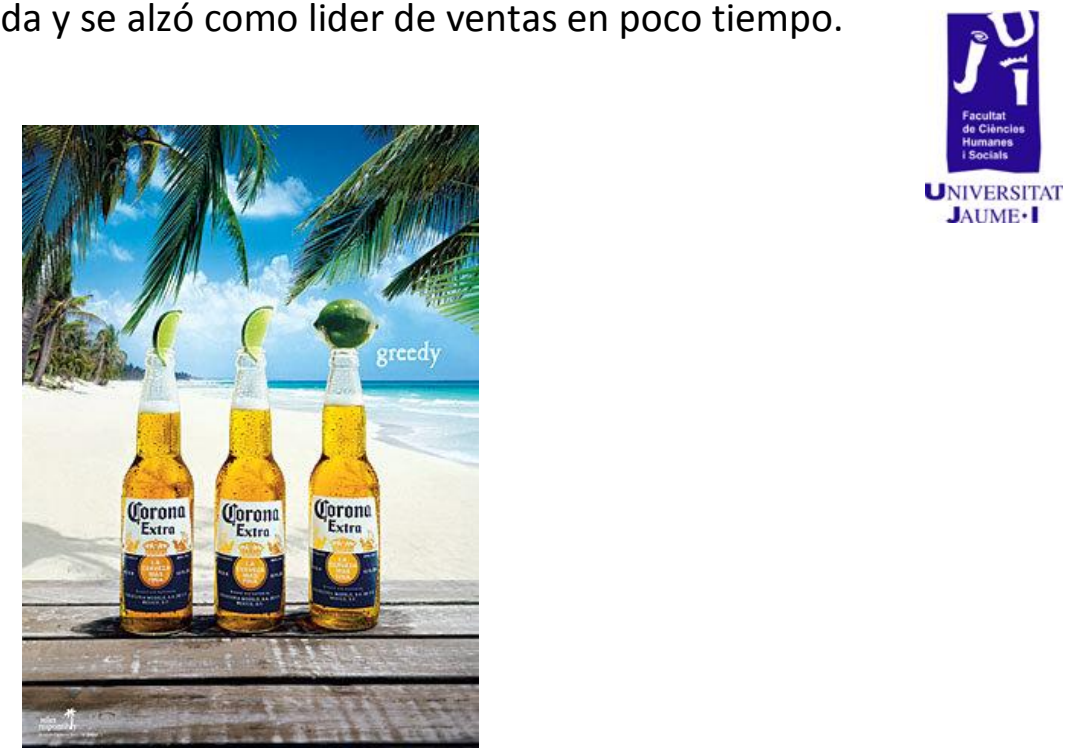

Las marcas que consiguen construirse gracias a un mito o una leyenda, adquieren una historia y obtienen una carga simbólica muy valiosa que revierte directamente en lla marca. Los consumidores, cada vez que consuman el producto, estan consumiendo el "mito" y construyendo por tanto su propia identidad, creando fuertes lazos con la marca.

\section{Factor de éxito 2: La Belleza Exterior.}

CASO LUCKY STRIKE: El diseñador industrial Raymond Loewy, autor del logotipo de Coca-Cola fue quien concibió el logotipo de esta marca de cigarrillos, verde militar en sus orígenes. Forzado en parte por la necesidad del pais de utilizar toda la tinta verde para la equipación de los soldados en la segunda guerra mundial, en 1940, Loewy se vio retado a cambiar el diseño y mejorarlo. Con dos pequeñas acciones, la duplicidad del logo -mostrandolo por las dos caras- y con el cambio de color de la cajetilla de verde a blanco -un color que transmitia pureza, limpieza y modernidad- Loewy gano 50mil dolares y la empresa disparó sus ventas.
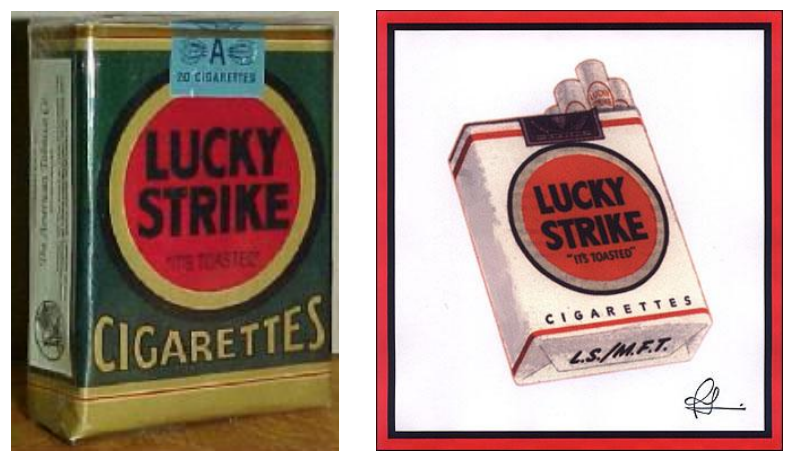

El Branding Emocional. Una aproximación heurística y profesional a su metodología y campos 
Volviendo al Mini, nuestro primer ejemplo, nos remitimos a Donald Norman, autor de "El Diseño Emocional", quien da la primera pista de porqué ha llegado éste al corazón de tanta gente. Es un coche que despierta sonrisas, por su manera de conducirlo, por su tamaño.. Su diseño y cómo fue concebido hace que el coche caiga bien, sea simpático.

"No se puede por menos que reconocer que casi ningún vehículo en nuestra historia reciente, ha suscitado tantas sonrisas", asegura Norman.

Asímismo, la introducción de colores supone un inmenso cambio a nivel sensorial. Un buen ejemplo de ellos fueron las pantallas de uso domestico -televisiones y ordenadores- en las que la introducción de los colores supuso un incremento considerable en la transmisión de sensaciones.

Además, hay que citar tambien la "novedad" como factor que asimismo incrementa la satisfacción en la experiencia de uso. Cuando se estrena un objeto se amplifica el placer sensorial y la sensación parece más gratificante. Por ejemplo, cuando conducimos un coche limpio, cortamos el cesped con una maquina nuevas, o dibujamos con un compás nuevo.. parece que el trazo nos va a salir mejor.

\section{Factor de éxito 3: un liderazgo auténtico y desinteresado}

CASO COCA-COLA. Del Mito al "Buen Ejemplo". Coca Cola ya había construido su primer mito -el de servidor de bebidas a los soldados de la 2a guerra mundial -mediante el cual, ejemplificando el orgullo de la nación, consiguió identificar sus emociones patrióticas a las del pueblo americano.

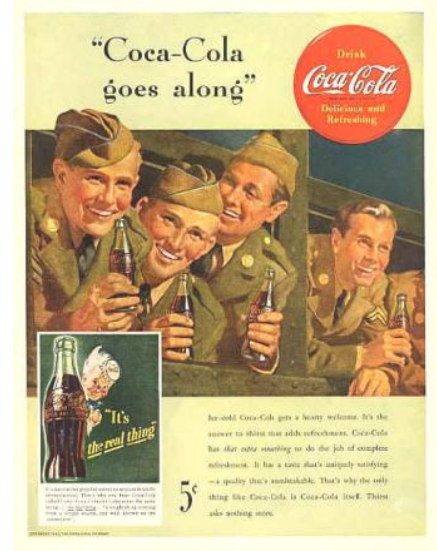

Pero a finales de los 60, tras los horrores de la guerra, y en medio de las protestas de la por la guerra de Vietnam, Cola Cola lanzó un mensaje de paz que dio la vuelta al mundo (anuncio "Hilltop" 1971), uniéndose y liderando el mensaje de fin a la guerra e igualdad social. 


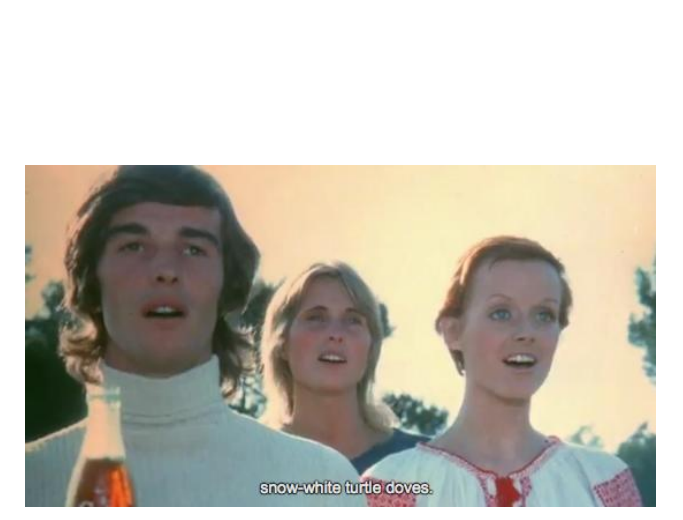

El convertirse en icono cultural no es nada fácil, pero es a lo que -más alla de los intereses comerciales- aspiran todas las marcas. Holt acuña el términdo "Cultural branding" como el conjunto de axiomas y principios estratégicos que guían la construcción de marcas en iconos culturales, y reafirma que las marcas que se convierten en iconos culturales aúnan las siguientes características:

Son Populistas, es decir, nacen del pueblo y crecen con el pueblo y están alejados de la búsqueda de status o poder. Vienen de la vida real y son auténticos.

Son lideres de cambios, no evocan beneficios ni siquiera presentan sus productos. Representan una nueva filosofía o estilo de vida.

Interpelan al espectador o consumidor para que este reconsidere ideas preconcebidas, para que reflexione. Dan por hecho el carácter activo del consumidor.

Se alinea con deseos incipientes de la sociedad

\section{Factor de éxito 3: Un carácter positivo, consistente e intelectualmente estimulante}

EL CASO APPLE. Para el lanzamiento del ordenador de $128 \mathrm{~K}$ de Mackintosh, Apple creo "1984", un spot inspirado en la novela de George Orwell, en el que una mujer de pelo corto, shorts y camiseta, irrumpía en una habitacion donde hombres escuchaban "hipnotizados" a una gran pantalla parlante: La valiente fémina, armada con un martillo, no duda en romper al "Dictador" y dejarlo sin habla. Este anuncio supuso la ruptura con la categoría existente de ordenadores domésticos y sentaría las bases de la personalidad de Apple. 


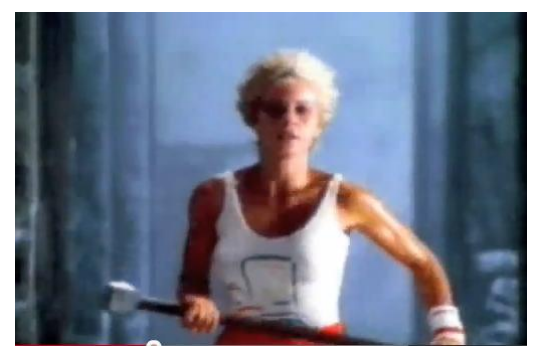

Años más tarde, en 1998, Apple lanzaba iMac con multitud de novedades en las uqe primaba la mejora de la experiencia: Introducia graficos, ratón, aportaba una diversidad de tipografías, prescindía del disquete... era un guiño al consumidor inteligente en todos los detalles: la i de iMac significaba Internet y tenía nuevos "sabores", que no colores.

El nuevo ordenador fue introducido de forma innovadora: El nuevo iMac y un poco mas tarde la campaña "Think Different" se presentó como un reto intelectual. Era una campaña inspiracional, enfocada a la expresión del genio creativo.

Según explica Aatker en su libro "Brand Relevance", las marcas desgastadas, de personalidad débil y no asociadas a la innovación son ininteresantes y pueden no ser relevantes para el consumidor a pesar de ser conocidas y creíbles.

Schmith, en su libro "Experiential Marketing", asegura que las marcas que se atreven a retar intelectual y creativamente al publico consiguen un alto nivel de conexión emocional de sus consumidores.

Por tanto podemos introducir aqui el beneficio de Onda Expansiva, puesto que si una marca con una personalidad potente, recoge experiencias de usuario positivas y se comunica bien con sus públicos, entonces será capaz de influenciar positivamente no solo en su imagen de marca, sino también en la categoría de producto a la que pertenece, cambiando la imagen del consumidor respecto a toda la categoría de forma positiva. Un ejemplo claro sería, y por continuar con Apple, la influencia positiva que ha generado el iPad en el antaño anodino mercado de las tablets, gracias a su carácter innovador.

\section{Factor de Exito 4: Manejar bien los afectos}

EL CASO IKEA: Ikea reproduce para sus consumidores una situación de consumo sensorial: en las tiendas se disponen los muebles como lo harían en una casa, de modo que la situacion de consumo emula la visita a una casa, en la que el consumidor prueba el producto, experimenta, mide, pesa. 

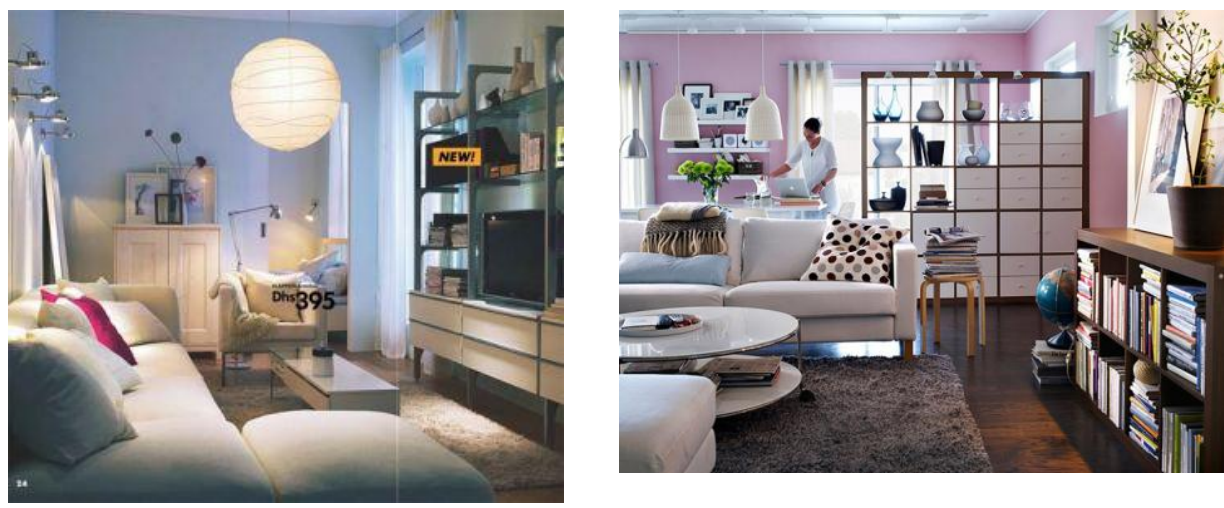

David Aatker, autor de "Brand Relevance" asegura que el consumo ocurre en una situación de afecto o emoción. Hay situaciones de consumo relacionadas con afecto positivos: quedar con una amiga para ir de compras, o tomar una bebida en una terraza frente al mar, o ir al cine bien acompañado/a, o al futbol a ver la final de la Champions de tu equipo... Sin duda estas situaciones están marcadas por una feliz sensación de agrado y excitación. Pero no todas la situaciones de consumo son positivas. Ir a comprar regalos el 24 de diciembre es estresante o comprar un bañador justo antes del verano, es incluso a veces vergonzoso.

Tambien cabe destacar que el "cara a cara" en las situaciones de compra levanta fuertes sensaciones, por lo que es muy importante por parte de las marcas, cuidar la interacción y el contacto humano en el punto de venta, y potenciar la empatía en sus vendedores.

Lindstrom, en su libro Brandsense asegura que el marketing tradicional esta muerto, y que las marcas necesitan entregar al cliente una completa experiencia sensorial. Hay que trabajar en experiencias que vayan más allá de la vista y el sonido, en la integración de los cinco sentidos "estrategia sensorial de la marca".

Dupuis y Le Jean Savreux, en su obra Marketing Experiencial, habla de que el consumidor como productor de sentido, de experiencias positivas o negativas a través del proceso de consumo. Son "co-productores" de experiencias en las que intervienen todos: los productores, distribuidores y los consumidores. El consumidor busca alentar su imaginación, sus sentidos, sus valores hedonistas, lúdicos, estéticos o espirituales.

Por todo ésto, la frecuencia de visita a la tienda no solamente esta motivada por la búsqueda de un producto o servicio, sino por otra serie de motivaciones personales, por la búsqueda de experiencias. 


\section{Discusión y conclusiones}

La principal conclusión a la que he llegado tras este estudio es que las marcas son cada vez más humanas.

En 1923, el famoso publicista de principios de siglo Bruce Barton dijo que el papel de la publicidad era ayudar a las grandes compañías a encontrar su alma. "Las empresas tienen alma, tal como la tienen las naciones y los hombres"

Más tarde, durante la década de los 80 , el gran publicista frances Jacques Seguela, ideo una plataforma creativa - la "Star Stratégie"- en la que trataba a las marcas y productos como personas que se hacen querer por su estilo, caracteristicas, personalidad.

En 2008, el Manifiesto Cluetrain anunciaba el inicio de una nueva era, en la que las marcas y las personas entablan una relacion casi personal. Aseguran que los negocios son fundamentalmente humanos, las conversaciones son la base de la nueva forma de hacer negocios. Hablan por ver primera de internet, de la libertad de los clientes activos, de la ruptura de jerarquías. Sentaron las bases de la humanización de las marcas y anticiparon un nuevo modelo en el que las nuevas herramientas como las redes sociales, permiten hoy el contacto directo marcaconsumidor.

Como principales caracteristicas "humanas", vemos que las marcas despiertan emociones: cuando se apoderan del espiritu del pasado, provocando nostalgia, o cuando se "antropomorfizan", tomando formas humanas, o cuando son capaces de unir a individuos solitarios con nuevos grupos de pertenencia... Además, las marcas se convierten en compañeros muy intimos, hacia los cuales sentimos verdadero odio si nos fallan, cuando por ejemplo, deslistan una colonia o un carmín, pueden hacernos sentir traicionados.

Por tanto, podemos afirmar que la marca ha dejado atrás su supremacía para volverse más humana, mas cercana y por tanto todo apunta a que la comunicacion publicitaria avanza hacia un modelo más personalizado y emocional, donde observamos que el desarrollo y la actualización de tecnicas de herramientas de branding emocional será la clave para llegar con más efectividad a sus consumidores.

\section{Bibliografía}

AAKER, David (2011): Brand Relevance, John Wiley and Sons Inc, New York.

CSIKSZENTMIHALI, Mihali (1981): The meaning of things. Domestic symbols and the self Cambridge University Press, Cambridge. 
Consol, Domenico (2012): "A New Concept of Marketing: The Emotional Marketing", BRAND Broad Research in Accounting, Negotiation, and Distribution, Volumen 1, Issue 1, Department of Business Studies and Law, University of Urbino, Italia

CostA, Joan (2004): La Imagen de Marca, un fenómeno social, Paidós, Barcelona.

GoBÉ, Marc (2005): Branding emocional: el nuevo paradigma para conectar las marcas emocionalmente con las personas, Divine Egg Publicaciones, Barcelona.

GolemAN, Daniel, (2008): Inteligencia emocional, Kairós, Barcelona.

HolT, Douglas B. (2004): How Brands Become Icons, Harvard Business School Publishing Corporation, Boston, Massachussets.

KAPFERER, Jean Nöel, (2007): Les Marques, capital de l'entreprise : créer et développer des marques fortes Éditions d'organisation, Paris.

KLEIN, Noemi (2001): No Logo, Paidós Ibérica, Barcelona.

LeVINE, Ric y otros (eds.) (2008): El Manifiesto Cluetrain: el ocaso de la empresa convencional Deusto, Barcelona

Mattelart, Armand (2007): Historia de la Sociedad de la Información, Paidós, Barcelona.

NORMAN, Donald A. (2005): El Diseño emocional: por qué nos gustan (o no) los objetos cotidianos, Paidós, Barcelona.

RICARTE, Jose María (1991): Una introducción al estudio y analisis de la naturaleza de la creatividad, considerada como producto específico de la comunicación publicitaria, Tesis Doctoral, Facultad de Ciencias de la Comunicación, Departamento de Comunicación Audiovisual y Publicidad, UAB, Barcelona

SCHMITT, Berm H. (1999): Experiential Marketing, The Free Press, New York

Touraine, Alain, (2009): La Mirada Social, Un marco de pensamiento distinto para el Siglo XXI, Paidós, Barcelona.

\section{Webgrafía}

Instalación TBWA Singapore para Mini

http://creativecriminals.com/ambient/mini-little-big-toy/

Instalación JWT Amsterdam para Mini

http://www.mpdailyfix.com/exclusive-story-behind-the-mini-cooper-

christmas-box-ads/ 
Anuncio Hilltop de Coca Cola

http://www.youtube.com/watch?v=FvTqW6on8MA)

Anuncio "1984" de Apple

http://www.youtube.com/watch?v=HhsWzJo2sN4

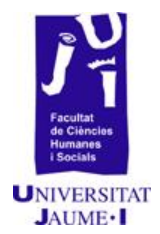

El Branding Emocional. Una aproximación heurística y profesional a su metodología y campos de innovación. Irene Nomdedeu 
